\title{
Editorial: Special Issue: Theories and Applications of Emerging Technologies in Civic Engagement
}

\author{
Jasmine McNealy * \\ University of Florida, Gainesville, FL, United States
}

Keywords: blockchain, civic, technology, critique, governance

\section{Editorial on the Research Topic}

Special Issue: Theories and Applications of Emerging Technologies in Civic Engagement

It would be an understatement to say that blockchain technology has garnered significant attention in the past few years. Though perhaps most popularly known in connection with cryptocurrencies like Bitcoin, blockchain has been proposed as a solution for data-related problems in several sectors including finance (Zheng et al., 2018), smart contracts (Yli-Huumo et al., 2016), and security (Biswas and Muthukkumarasamy, 2016). At the same time, blockchain has been criticized as being somewhat of a buzzword, set, like so many other technological innovations, to never live up to the hype (Yaga et al., 2018). Some have pegged blockchain as one of many technosolutionist tools that do not bring about the benefits that its proponents claim. Yet scholars, practitioners, and government officials are investigating the possibilities of blockchain to remedy some of the most pressing problems wanting a solution.

Called simply, at times, a distributed ledger, blockchain is as its name specifies. It is a digital chain of blocks, each recording the transactions that have happened in the system. These blocks do not have to be centrally located, allowing multiple participants to create a federated system of recorded transactions. Interactions between parties are simplified through enhanced transparency. Blockchain systems can be either permissionless or permissioned. Permissionless systems allow anyone to join and add blocks. Permissioned systems require those wanting to participate to be allowed to join through either the consensus of the other participants, or permission from a centralized authority, such as organizational management. The kind of blockchain system created has implications for how the system is used.

A question arises, however, as to whether blockchain technology should be used at all. Some scholars argue that blockchain should only be used, "when multiple mutually mistrusting entities want to interact and change the state of a system, and are not willing to agree on an online trusted third party" (Wüst and Gervais, 2018, p. 46) Otherwise, they suggest the use of a simple database or system already available. Other critics of blockchain argue that at most technology is nothing more than a hyped-up ledger system, claiming that the distributed systems are inefficient in comparison to traditional centralized systems (Yaga et al., 2018). A third criticism of implementing particularly permissionless blockchain is that privacy is limited because anyone can join (Lo et al., 2017). Critics also question the scalability of blockchain, as current systems do not have the same ability to process transactions as mainstream systems (Lo et al., 2017). Nevertheless, blockchains are being considered for various implementations in corporate, civil society, and government sectors.

This special issue offers several investigations into the implications of blockchain in various civic contexts. Like industry, governments and civil society organizations have begun examining the potential for uses of blockchain technology in the administration of public services, social programs, and other municipal, and community situations. Prior to this issue, blockchains have been posited as 
being able to act as "civic nervous systems," eliminating the need for a centralized directorate and allowing peer-to-peer problemsolving (Voto, 2017). This remains to be seen, but the five articles that comprise this special issue offer insight into how blockchain is being tested for use for civic engagement.

\section{WHO WATCHES THE WATCHMEN? A REVIEW OF SUBJECTIVE APPROACHES FOR SYBIL-RESISTANCE IN PROOF OF PERSONHOOD PROTOCOLS (BERMAN, SIDDARTH, IVLIEV, SIRI)}

In their review of the academic literature on several approaches to identity verification, Siddarth et al. use the Sybil attack, in which fake virtual personas are created, as a barometer for evaluating the best identity varying technologies. Those found to be the best all use a form of subjectivity including voting, bouching, and interpreting, among other subjective inputs, to arrive at consensus.

\section{THE DEMOCRACY TO COME? AN ENQUIRY INTO THE VISION OF BLOCKCHAIN-POWERED E-VOTING START-UPS (IMPERIAL)}

Imperial investigates the use of blockchain for e-voting and possible implications for the democratic process. To do this, the author conducted critical discourse analyses of the web publications of seven blockchain-powered e-voting (BPE) startup organizations, finding a significant difference between organizational and widely accepted understandings of democracy. Instead, the research found that the BPE startup organizational communications offered a view of democracy that could potentially negatively impact voter decision-making, as it focuses predominantly on one particular kind of expression.

\section{FROM ATHENS TO THE BLOCKCHAIN: ORACLES FOR DIGITAL DEMOCRACY (POBLET, ALLEN, KONASHEVYCH, LANE, VALDIVIA)}

Poblet et al. examine the use of oracles in blockchain uses related digital democracy platforms. To do this, they first detail the historic uses of oracles-trusted third-parties used to provide an external examination of a system. The researchers then proposed an approach to using distributed oracles in digital democracy settings, or tools allowing participatory processes. These oracles would act as knowledge management interfaces offering efficient administration of platforms for particular purposes, including injecting expert knowledge, data and information, supplying data about voting within the platform, and enabling dispute resolution processes. At the same time, oracles are not without limitations and challenges for implementation.

\section{DECENTRALIZED JUSTICE: A COMPARATIVE ANALYSIS OF BLOCKCHAIN ONLINE DISPUTE RESOLUTION PROJECTS (AST, AOUIDEF, AND DEFFAINS)}

Aouidef et al. examine decentralized justice-an approach to dispute resolution combining blockchain, crowdsourcing, and game theory. Decentralized justice systems have arisen in response to the exponential growth in digital transactions that makes it infeasible for an international court system to handle, particularly as jurisdictional issues emerge with cross-border interactions. The authors investigate the stakeholders as well as the design mechanisms and possible future of decentralized justice systems.

\section{CAN DISTRIBUTED LEDGER TECHNOLOGIES PROMOTE TRUST FOR CHARITIES? A LITERATURE REVIEW (CHRISTIE)}

In a review of the literature on stakeholder trust and distributed ledger technology for charitable organizations, Christie found three main themes: key definitions, views on the decline of trust in charitable industries, and how distributed ledgers, particularly blockchain, has the potential for promoting trust. Trust was hypothesized as being correlated to the decentralized nature of the technology, provenance, and rule enforcement. In conducting the review, the author found several areas where a dearth in the literature existed including, inconsistency in the treatment of key concepts, and a lack of critical consideration of the potential for negative impacts on stakeholder trust that could arise from the deployment of blockchain technology by charitable organizations.

As a whole, these research and review contributions assist in providing both an overview of emerging and ongoing issues in the use of blockchain technology for civic engagement.

\section{AUTHOR CONTRIBUTIONS}

The author confirms being the sole contributor of this work and has approved it for publication. 


\section{REFERENCES}

Biswas, K., and Muthukkumarasamy, V. (2016). "Securing Smart Cities Using Blockchain Technology," in 2016 IEEE 18th International Conference on High Performance Computing and Communications; IEEE 14th International Conference on Smart City; IEEE 2nd International Conference on Data Science and Systems (HPCC/SmartCity/DSS), Sydney, NSW, Australia, December 12-14, 2016. (IEEE), 1392-1393. doi:10.1109/HPCC-SmartCityDSS.2016.0198

Lo, S. K., Xu, X., Chiam, Y., and Lu, Q. (2017). "Evaluating Suitability of Applying Blockchain," in 2017 22nd International Conference on Engineering of Complex Computer Systems (ICECCS), Fukuoka, Japan, November 5-8, 2017. (IEEE), 158-161. doi:10.1109/ICECCS.2017.26

Voto, A. (2017). Blockchains and the Civic Nervous System. Field Actions Science Reports. J. Field Act. 17, 60-63.

Wüst, K., and Gervais, A. (2018). "Do you Need a Blockchain?," in 2018 Crypto Valley Conference on Blockchain Technology (CVCBT), Zug, Switzerland, June 20-22, 2018. (IEEE), 45-54. doi:10.1109/CVCBT.2018.00011
Yaga, D., Mell, P., Roby, N., and Scarfone, K. (2018). Blockchain Technology Overview. arXiv. doi:10.6028/NIST.IR.8202

Yli-Huumo, J., Ko, D., Choi, S., Park, S., and Smolander, K. (2016). Where Is Current Research on Blockchain Technology?-A Systematic Review. PLos One 11 (10), e0163477. doi:10.1371/journal.pone.0163477

Zheng, Z., Xie, S., Dai, H. N., Chen, X., and Wang, H. (2018). Blockchain Challenges and Opportunities: A Survey. Int. J. Web Grid Serv. 14 (4), 352-375. doi:10.1504/IJWGS.2018.095647

Conflict of Interest: The author declares that the research was conducted in the absence of any commercial or financial relationships that could be construed as a potential conflict of interest.

Copyright $\odot 2021$ McNealy. This is an open-access article distributed under the terms of the Creative Commons Attribution License (CC BY). The use, distribution or reproduction in other forums is permitted, provided the original author(s) and the copyright owner(s) are credited and that the original publication in this journal is cited, in accordance with accepted academic practice. No use, distribution or reproduction is permitted which does not comply with these terms. 